\title{
ATTITUDES AND ACHIEVEMENT IN STATISTICS: A META-ANALYSIS STUDY
}

\author{
ESMA EMMİOĞLU \\ Gaziosmanpasa University, Turkey \\ esma.Emmioglu@gmail.com \\ YESIM CAPA-AYDIN \\ Middle East Technical University, Turkey \\ capa@metu.edu.tr
}

\begin{abstract}
This study examined the relationships among statistics achievement and four components of attitudes toward statistics (Cognitive Competence, Affect, Value, and Difficulty) as assessed by the SATS. Meta-analysis results revealed that the size of relationships differed by the geographical region in which the studies were conducted as well as by the component of statistics attitudes being examined. Medium effect sizes were found between statistics achievement and scores on the Affect and Cognitive Competence components for studies conducted in the United States whereas those conducted in other countries yielded small effect sizes. The Value and Difficulty components exhibited small effect sizes for both regions. In every case, the U.S. effect sizes were about double in size in comparison to those from non-U.S. countries.
\end{abstract}

Keywords: Statistics education research; Statistics achievement; Statistics attitudes

\section{INTRODUCTION}

Statistics is an important tool for any individual in today's world in which numerical data are increasingly presented (Ben-Zvi \& Garfield, 2010). Accordingly, students from a broad spectrum of disciplines take statistics courses in higher education. We believe that, in order for students to succeed and to use statistics, they should think that statistics is valuable in their lives. We also believe that it is important for students to like statistics, believe that they can understand and use statistics, and think that statistics is not too difficult. In other words, it is important for students to have positive attitudes toward statistics (Schau, 2003b). Based on others' definitions of attitudes (e.g., Aiken, 2002; Ajzen, 2005), we define attitudes toward statistics as a multidimensional construct representing students' learned predispositions to respond positively or negatively to statistics.

In order to measure students' attitudes toward statistics, several surveys have been developed. The Survey of Attitudes Toward Statistics (SATS; Schau 1992, 2003a) is one of the most widely used instruments assessing statistics attitudes.

The SATS-28 was originally developed with a four-component structure including Affect, Cognitive Competence, Value, and Difficulty (Hilton, Schau, \& Olsen, 2004; Schau, Stevens, Dauphinee, \& Del Vecchio, 1995). Based on Eccles and colleagues' expectancy value theory (Wigfield \& Eccles, 2002), it then was revised to create the SATS-36 by including two additional components: Effort and Interest (www.evaluationandstatistics.com). In keeping with this strong theoretical background, the SATS assumes a multidimensional structure of attitudes toward statistics (Ramirez, Schau, \& Emmioğlu, 2012). Both versions of the SATS have been used in many studies that involved samples of students from different educational levels, majors, and nationalities. These studies provided evidence supporting good psychometric properties for component scores from both versions (e.g., Bechrakis, Gialamas, \& Barkatsas, 2011; Chiesi \& Primi, 2009; Emmioğlu, CapaAydin, \& Cobanoglu, 2010; Dauphinee, Schau, \& Stevens, 1997; Hilton et al.; Schau, et al.; Tempelaar, Schim van der Loeff, \& Gijselaers, 2007).

Statistics Education Research Journal, 11(2), 95-102, http://www.stat.auckland.ac.nz/serj C International Association for Statistical Education (IASE/ISI), November, 2012 
The four-factor structure of the SATS has been validated using confirmatory factor analysis; the results from these analyses showed a very good fit of the hypothesized model to the data (Dauphinee et al., 1997; Hilton et al., 2004; Schau et al., 1995). More recently, the six-factor structure of the newer SATS has been validated, using confirmatory factor analysis, and again the results demonstrated a very good fit of the data to the model (e.g., Emmioğlu, 2011; Tempelaar et al., 2007; Verhoeven, 2009).

The results from these studies using the SATS-28 and the SATS-36 reported adequate to high internal consistency values for all components. Cronbach's alpha values were in the following ranges: Affect $=0.80$ to 0.85 , Cognitive Competence $=0.77$ to 0.82 , Value $=0.78$ to 0.90 , Difficulty $=0.64$ to 0.75 , Interest $=0.80$ to 0.84 , and Effort $=0.76$ to 0.81 .

We agree with Schau (2003b) that statistics attitudes involve at least the four components assessed by the SATS-28: Cognitive Competence, Value, Affect, and Difficulty. In our work, we would have liked to have included the two additional components contained in the SATS-36, but unfortunately little research exists that relates scores on these two components to achievement.

A growing body of research has shown that attitudes toward statistics are positively related to students' achievement in statistics courses, indicating that more positive attitudes are related to higher achievement (e.g., Chiesi \& Primi, 2009; Dempster \& McCorry, 2009; Limpscomb, Hotard, Shelley, \& Baldwin, 2002; Sorge \& Schau, 2002), although the strength of these relationships varied. By themselves, individual studies may produce contradictory results. To our knowledge, there has not been a meta-analytic study that provides a systematic statistical synthesis of the results from these individual studies.

Meta-analysis integrates findings across studies to reveal simpler patterns of relationships that may underlie research literatures. Meta-analysis not only summarizes study findings but also corrects for the distorting effects of sampling error, measurement error, and other artifacts that produce the illusion of conflicting findings (Hunter \& Schmidt, 2004). A meta-analysis is performed by defining an effect size measure that represents an overall numerical result from each study. Effect size, in this context, is defined as a measure of the strength of a relationship (Borenstein, Hedges, Higgins, \& Rothstein, 2009). The two main families of effect sizes in meta-analysis are the standardized mean difference and the Pearson correlation coefficient (Rosenthal, 1995). Because the purpose of our study was to explore the relationships between post-secondary students' attitudes toward statistics and their statistics achievement, we used Pearson correlation coefficients as the measure of effect size. Specifically, the following research questions were addressed:

1. What is the relationship between statistics achievement and students' Affect toward statistics?

2. What is the relationship between statistics achievement and students' attitudes about their Cognitive Competence in relation to statistics?

3. What is the relationship between statistics achievement and the Value students attribute to statistics?

4. What is the relationship between statistics achievement and students' attitudes toward the Difficulty of statistics?

\section{METHODS AND DESIGN}

In order to conduct our meta-analyses, we first searched for relevant studies. Computer searches were conducted using several databases (i.e., ERIC, Web of Science, Dissertations and Theses from Proquest). The search was done by asking for studies with the phrases of "Statistics attitudes OR attitudes toward statistics" in their "titles." In August 2012, we found 56 studies from the Web of Science database, 40 from ERIC, and 30 from Dissertations and Theses from Proquest.

Second, we filtered the studies using several selection criteria. Studies were retained if they

1. had post-secondary education students as participants,

2. reported the Pearson correlation coefficient between students' attitudes toward statistics and statistics achievement,

3. measured statistics attitudes using the Survey of Attitudes Toward Statistics,

4. reported at least one of the four components found in the SATS-28 (Cognitive Competence, Affect, Value, and Difficulty), and 
5. reported post-course attitudes, because most studies reported post-course attitudes toward statistics rather than pre-course attitudes.

After applying the above criteria, we retained 17 studies. The year of publication of these studies ranged from 1998 to 2011. These studies were conducted in eight different countries: United States (Cashin \& Elmore, 2005; Finney \& Schaw, 2003; Schau, 2003b; Schau, personal communication,2010; Schutz, Drogosz, White, \& Distefano, 1998; Scott, 2001; Sorge \& Schau, 2002; Stone et al., 2003), Italy (Chiesi \& Primi, 2009, 2010), United Kingdom (Demspter \& McCorry, 2009), Turkey (Emmioğlu, 2011; Emmioğlu et al., 2010), Spain (Estrada \& Batanero, 2008), Israel (Nasser, 2004), Netherlands (Tempelaar, Gijselaers, \& Schim van der Loeff, 2006), and Switzerland (Zimprich, 2012). These studies used various methods to measure students' statistics achievement including statistics grades and exams. Three studies used standardized instruments. Tempelaar et al. and Estrada and Batanero used the Statistical Reasoning Assessment (SRA) instrument (Garfield, 2003) and Stone et al. used the Statistics Concept Inventory (SCI) to measure students' statistics achievement. The SRA, a multiple-choice test, was developed to assess students' statistical reasoning for a sample of statistical concepts (Garfield, 2002). Stone et al. described SCI as a "multiple choice testing instrument that is being developed to assess student understanding of fundamental statistics concepts and to identify commonly held misconceptions" (p. 1).

Lastly, we analyzed the statistical significance, magnitude, and homogeneity of the estimated effect sizes for each of the four attitude components separately using the Comprehensive MetaAnalysis software (Borenstein, Hedges, Higgins, \& Rothstein, 1998-2005) to conduct weighted analyses. Hedges and Olkin's $Q$ statistic was applied to test the homogeneity of the correlations for each attitude component. We used the following criteria to assess the effect size magnitudes: small ( $r$ $\left.<0.30, r^{2}<0.09\right)$, moderate $\left(0.30 \leq r<0.50,0.09 \leq r^{2}<0.25\right)$, and large $\left(r \geq 0.50, r^{2} \geq 0.25\right)$ (Cohen, 1988).

Because in almost all cases the same subjects contributed scores to each of the four attitude components, we used a Bonferroni adjustment to adjust for the reuse of subjects. To maintain an overall alpha of 0.05 and an overall confidence interval of $95 \%$, we used a test-wise $p$-value of 0.01 $(0.05 / 4=.0125$ rounded to 0.01$)$ and a confidence level of $99 \%$. We applied fixed effect modeling (Hedges \& Vevea, 1998) as the studies for the meta-analyses do not represent a random sample of all studies that investigate the statistics attitudes-achievement relationship.

\section{RESULTS}

As Table 1 shows, studies included in the meta-analysis were highly variable in terms of sample sizes. They ranged from 49 (Emmioğlu et al., 2010) to 2,715 (Schau, personal communication, 2010). Similarly, the correlation coefficients relating attitudes and achievement varied across studies and across components. The majority of studies reported positive relationships between each attitude component and achievement. Generally, statistics achievement had higher correlations with Cognitive Competence and Affect, than with Value and Difficulty. The size of these relationships varied from small to large, with most of them falling in the small ranges. The largest correlation coefficient between statistics achievement and Affect was 0.60 (Finney \& Schaw, 2003, U.S.) whereas the lowest was 0.12 (Tempelaar et al., 2006, Netherlands). Similarly, the strongest correlation between statistics achievement and Cognitive Competence was $r=0.64$ (Finney \& Schaw) and the lowest was 0.12 (Tempelaar et al.). The largest correlation between statistics achievement and Value was 0.42 (Finney \& Schaw) whereas the lowest was 0.03 (Scott, 2001, U.S.). Lastly, the highest correlation between statistics achievement and Difficulty was 0.51 (Finney \& Schaw) and the lowest was 0.01 (Scott). Interestingly, Finney and Schaw (U.S.) reported the strongest relationships between statistics achievement and each of the four attitude components. Tempelaar et al. (Netherlands) and Scott (U.S.) reported the weakest relationships. Results from these research studies together clearly suggest that attitudes and achievement are related. 
Table 1. Sample sizes and correlation coefficients between attitude components and statistics achievement for each study

\begin{tabular}{lllcccc}
\hline Study & Country & $n$ & Affect & Cog Comp & Value & Difficulty \\
\hline Cashin \& Elmore, 2005 & U.S. & 342 & $.45^{*}$ & $.43^{*}$ & $.32^{*}$ & $.30^{*}$ \\
Finney \& Schaw, 2003 & U.S. & 103 & $.60^{*}$ & $.64^{*}$ & $.42^{*}$ & $.51^{*}$ \\
Schau, 2003b & U.S. & 268 & $.35^{*}$ & $.36^{*}$ & $.30^{*}$ & $.17^{*}$ \\
Schau, 2010 & U.S. & & $.40^{*}$ & $.40^{*}$ & 0.28 & $.26^{*}$ \\
Schutz et al., 1998 & U.S. & 94 & 0.21 & $.48^{*}$ & 0.16 & - \\
Sorge \& Schau, 2002 & U.S. & 264 & $.35^{*}$ & $.27^{*}$ & 0.09 & $.22^{*}$ \\
Scott, 2001 & U.S. & 91 & 0.16 & 0.16 & 0.03 & 0.01 \\
Stone et al., 2003 & U.S. & 139 & $.26^{*}$ & $.32^{*}$ & $.33^{*}$ & $.25^{*}$ \\
Chiesi \& Primi, 2009 & Italy & 232 & $.29^{*}$ & $.29^{*}$ & $.20^{*}$ & $.17^{*}$ \\
Chiesi \& Primi, 2010 & Italy & 487 & $.27^{*}$ & $.26^{*}$ & $.19^{*}$ & $.20^{*}$ \\
Demspter \& McCorry, 2009 & U.K. & 82 & 0.23 & $.31^{*}$ & 0.23 & -0.05 \\
Estrada \& Batanero, 2008 & Spain & 367 & $.20^{*}$ & $.26^{*}$ & $.22^{*}$ & 0.09 \\
Tempelaar et al., 2006 & Netherlands & 2031 & $.12^{*}$ & $.12^{*}$ & $.10^{*}$ & $.11^{*}$ \\
Zimprich, 2012 & Switzerland & 346 & - & - & - & $.25^{*}$ \\
Emmioğlu, 2011 & Turkey & 214 & $.34^{*}$ & $.36^{*}$ & 0.16 & 0.08 \\
Emmioğlu et al., 2010 & Turkey & 49 & $.45^{*}$ & $.26^{*}$ & 0.33 & 0.31 \\
Nasser, 2004 & Israel & 162 & 0.18 & $.28^{*}$ & 0.12 & 0.11 \\
\hline N & & & & &
\end{tabular}

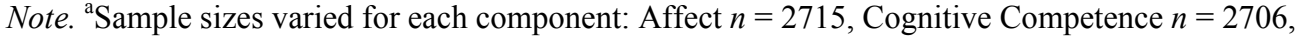

Value $n=2693$, Difficulty $n=2712$.

${ }^{*} p<.01$, two-tailed.

As presented in Table 2, combining studies, the meta-analysis results showed statistically significant positive relationships between attitudes and achievement for each component. For Affect, the overall global correlation coefficient of 0.30 was a medium effect size. Studies with participants who liked statistics better also achieved at a higher level. Likewise, for the Cognitive Competence component, the results revealed a medium overall effect size of 0.30 . That is, overall, studies with participants who reported higher Cognitive Competence in relation to statistics also exhibited higher statistics achievement. The analysis of the Value component revealed a small overall effect size of 0.21 . Studies with participants who valued statistics more also performed at a higher achievement level. Similarly, the analysis for the Difficulty component revealed an overall effect size of 0.20 . Studies with participants who thought statistics was easier had higher statistics achievement. However, as the variability across studies and across attitude components in the original studies suggested, Hedges and Olkin's $Q$ statistic revealed heterogeneity for the correlation coefficients included in each meta-analysis. These results indicate that the studies do not share a common effect size for any of the four attitude components (Borenstein et al., 2009).

Table 2. Meta-analysis correlation coefficients, confidence intervals, $Q$ statistic, overall and by region

\begin{tabular}{|c|c|c|c|c|}
\hline & & Overall & U.S. & Non-U.S. \\
\hline Affect & $\begin{array}{r}r \\
95 \% \text { CI } \\
\text { Q statistic }\end{array}$ & $\begin{array}{c}.30 \\
.28-.32 \\
Q(15)=146.87^{*}\end{array}$ & $\begin{array}{c}.39 \\
.36-.42 \\
Q(7)=23.22 *\end{array}$ & $\begin{array}{c}.18 \\
15-.21 \\
Q(7)=25.93 *\end{array}$ \\
\hline $\begin{array}{l}\text { Cognitive } \\
\text { Competence }\end{array}$ & $\begin{array}{r}r \\
95 \% \mathrm{CI} \\
\text { Q statistic } \\
\end{array}$ & $\begin{array}{c}.30 \\
.28-.32 \\
Q(15)=145.77 *\end{array}$ & $\begin{array}{c}.39 \\
.37-.42 \\
Q(7)=25.69 *\end{array}$ & $\begin{array}{c}.19 \\
.16-.22 \\
Q(7)=27.80^{*}\end{array}$ \\
\hline Value & $\begin{array}{r}r \\
95 \% \mathrm{CI} \\
\text { Q statistic }\end{array}$ & $\begin{array}{c}.21 \\
.19-.23 \\
Q(15)=65.91 *\end{array}$ & $\begin{array}{c}.27 \\
.24-.30 \\
Q(7)=20.79 *\end{array}$ & $\begin{array}{c}.14 \\
.11-.17 \\
Q(7)=10.70\end{array}$ \\
\hline Difficulty & $\begin{array}{r}r \\
95 \% \mathrm{CI} \\
\mathrm{Q} \text { statistic } \\
\end{array}$ & $\begin{array}{c}.20 \\
.17-.22 \\
Q(15)=64.83 * \\
\end{array}$ & $\begin{array}{c}.26 \\
.23-.29 \\
Q(6)=17.99 *\end{array}$ & $\begin{array}{c}.13 \\
.10-.16 \\
Q(8)=14.50 \\
\end{array}$ \\
\hline
\end{tabular}


An examination of Table 1 revealed that the correlation coefficients reported for the U.S. studies are generally higher than those for the other studies. This suggests that the heterogeneity among the correlation coefficients may be due to region. To examine this possibility, the analyses were repeated, dividing the studies into those conducted in the United States (where the SATS was developed and tested) and those that were conducted in other countries. The confidence intervals in Table 2 suggest that the relationship between achievement and every component of attitudes for studies conducted in the United States differs significantly from those conducted in other countries. The global correlation coefficient for each component is about twice as large for U.S. studies as the corresponding coefficient for studies conducted in other countries.

However, even taking region of study into account, the $Q$ statistic values for the Affect and Cognitive Competence components remained statistically significant both for the U.S. and non-U.S. studies, indicating remaining variability within these sets of correlations. For the Value and Difficulty components, the $Q$ statistic was not statistically significant for the non-U.S. studies whereas it was statistically significant for the U.S. studies.

\section{DISCUSSION}

Results from individual studies that have examined the relationship between post-secondary students' attitudes toward statistics and statistics achievement most often reported that attitudes toward statistics are positively related to students' achievement in statistics courses (e.g., Chiesi \& Primi, 2009; Dempster \& McCorry, 2009; Sizemore \& Lewandowski, 2009; Sorge \& Schau, 2002; Tempelaar et al., 2007). These studies were conducted in different countries, varied in sample sizes, used different measures to assess statistics achievement, and included students with often widely differing characteristics and majors, taught in a variety of statistics courses. In the current study, we synthesized the results of these studies by using meta-analysis methodology.

Hunter and Schmidt (2004) stated that meta-analysis can answer questions that were never addressed in any of the individual studies. Our study revealed consistently significant positive relationships between students' attitudes toward statistics and statistics achievement. However, the correlation coefficients across studies were heterogeneous for each attitude component. We observed that the region appeared to have an impact on these statistics attitude-achievement relationships: the U.S. data had a distinctly different pattern from the non-U.S. data. Subsequently, we divided the studies into two groups: those done in the U.S. and those done in other countries. (We could not further examine the results for differences in the second group because of the limited number of studies in each country.) Indeed, the size of relationships differed by the geographical region in which the studies were conducted as well as by the component of statistics attitudes being examined.

Medium effect sizes were found between statistics achievement and scores on the Affect and Cognitive Competence components for studies conducted in the United States whereas those conducted in other countries yielded small effect sizes. The Value and Difficulty components exhibited small effect sizes for both regions. In every case, the U.S. effect sizes were about double in size in comparison to those from non-U.S. countries.

Even considering the impact of region, six of the eight groups of correlation coefficients remained heterogeneous; only those coefficients for Value and Difficulty in non-U.S. countries were homogeneous. This heterogenity may be a result of sample differences including, for example, differences across studies in gender, major, and education level distributions; different course structures; and especially differences in the measures used to assess statistics achievement. Unfortunately, at least some of these important study characteristics are often omitted and so cannot be included as factors in meta-analyses.

The true relationships among attitudes and achievement are likely stronger than those observed in the studies we analyzed because the measures of these constructs contain error. We know that the SATS-28 scores have good to excellent psychometric properties, although they still contain error. Usually, we know very little about the error in the achievement measures used because most of them were created by the course instructors who did not evaluate their psychometric properties; these teacher-made tests and grades likely contained significant amounts of error. Even the standardized achievement measures used contain error. 
Our results suggest a variety of future research studies. First, the possible causes of regional differences in statistics attitudes-achievement relationships should be explored. Second, as more studies are published that utilize the SATS, research can examine possible causes for the heterogeneous results that remained after region is considered. Third, meta-analyses that include all statistics attitudes-achievement research, regardless of the attitude survey used, should be conducted. These analyses will be difficult because of the variety of attitude components assessed by various measures, as well as by the confusion of names given to these components (see Ramirez et al., 2012). Fourth, we suggest more research on the practical significance of attitudes on students' statistics achievement in statistics courses and use of statistics after taking their courses.

\section{ACKNOWLEDGEMENTS}

This article is a major revision and extension of a paper we presented at the 58th World Statistics Congress of the International Statistical Institute, 2011. We thank Dr. Ulas Ustun for his valuable contribution.

\section{REFERENCES}

Aiken, L. R. (2002). Attitudes and related psychological constructs: Theories, assessment and research. Thousand Oaks, CA: Sage Publication.

Ajzen, I. (2005). Attitudes, personality, and behavior (2nd ed.). New York: Open University Press.

Bechrakis, T., Gialamas, V., \& Barkatsas, A. N. (2011). Survey of Attitudes Toward Statistics (SATS): An investigation of its construct validity and its factor structure invariance by gender. International Journal of Theoretical Educational Practice, 1(1), 1-15.

Ben-Zvi, D., \& Garfield, J. (2010). Introducing the emerging discipline of statistics education. School Science and Mathematics, 108(8), 355-361.

Borenstein, M., Hedges, L., V., Higgins J. P. T., \& Rothstein, H. R. (1998-2005). Comprehensive Meta-Analysis (version 2.2). Englewood, NJ: Biostat.

Borenstein, M., Hedges, L. V., Higgins, J. P. T., \& Rothstein, H. R. (2009). Introduction to metaanalysis. West Sussex, UK: John Wiley \& Sons.

Cashin, S. E., \& Elmore, P. B. (2005). The Survey of Attitudes Toward Statistics scale: A construct validity study. Educational and Psychological Measurement, 65(3), 509-524.

Chiesi, F., \& Primi, C. (2009). Assessing statistics attitudes among college students: Psychometric properties of the Italian version of the Survey of Attitudes Toward Statistics (SATS). Learning and Individual Differences, 19(2), 309-313.

Chiesi, F., \& Primi, C. (2010). Cognitive and non-cognitive factors related to students' statistics achievement. Statistics Education Research Journal, 9(1), 6-26.

[Online: $\mathrm{http}: / / w w w . s t a t . a u c k l a n d . a c . n z / \sim i a s e / s e r j / S E R J 9 \% 281 \% 29$ Chiesi_Primi.pdf]

Cohen, J. (1988). Statistical power analysis for the behavioral sciences (2nd ed.). Hillsdale, NJ: Lawrence Erlbaum.

Dauphinee, T. L., Schau, C., \& Stevens, J. J. (1997). Survey of Attitudes Toward Statistics: Factor structure and factorial invariance for women and men. Structural Equation Modeling, 4(2), 129 141.

Dempster, M., \& McCorry, N. K. (2009). The role of previous experience and attitudes toward statistics in statistics assessment outcomes among undergraduate psychology students. Journal of Statistics Education, 17(2).

[Online: http://www.amstat.org/publications/jse/v17n2/dempster.html]

Emmioğlu, E. (2011). The relationship between mathematics achievement, attitudes toward statistics, and statistics outcomes: A structural equation model analysis (Unpublished doctoral dissertation). Middle East Technical University, Ankara, Turkey.

Emmioğlu, E., Capa-Aydin, Y., \& Cobanoglu, R. (2010, September). Lisansüstü öğrencilerin istatistiğe yönelik tutumu ile istatistik başarısı arasındaki ilişkinin iİncelenmesi. Paper presented at the National Congress of Educational Sciences, Lefkosa, Cyprus.

Estrada, A., \& Batanero, C. (2008). Explaining teachers' attitudes towards statistics. In C. Batanero, G. Burrill, C. Reading, \& Rossman, A. (Eds.) A joint ICMI/IASE study: Teaching statistics in 
school mathematics. Challenges for teaching and teacher education. Proceedings of the ICMI Study 18 and IASE 2008 round table conference. Monterrey, Mexico: International Commission on Mathematical Instruction and International Association for Statistical Education.

Finney, S. J., \& Schaw, G. (2003). Self-efficacy beliefs in college statistics courses. Contemporary Educational Psychology, 28(2), 161-186.

Garfield, J. B. (2002). The challenge of developing statistical reasoning. Journal of Statistics Education, 10(3).

[Online: http://www.amstat.org/publications/jse/v10n3/garfield.html]

Garfield, J. B. (2003). Assessing statistical reasoning. Statistics Education Research Journal, 2(1), $22-38$.

[Online: http://www.stat.auckland.ac.nz/ iase/serj/SERJ2\%281\%29.pdf\#page=24]

Hedges, L. V., \& Vevea, J. L. (1998). Fixed- and random-effects models in meta-analysis. Psychological Methods, 3(4), 486-504.

Hilton, S. C., Schau, C., \& Olsen, J. A. (2004). Survey of Attitudes Toward Statistics: Factor structure invariance by gender and by administration time. Structural Equation Modeling, 11(1), 92-109.

Hunter, J. E., \& Schmidt, F. L. (2004). Methods of meta-analysis: Correcting error and bias in research findings (2nd ed.). Thousand Oaks, CA: Sage Publications.

Limpscomb, T., Hotard, D., Shelley, K., \& Baldwin, Y. (2002, April). Business students' attitudes toward statistics: A preliminary investigation. Paper presented at the Allied Academies International Conference Academy of Educational Leadership, Nashville, TN.

Nasser, F. M. (2004). Structural model of the effects of cognitive and affective factors on the achievement of Arabic speaking pre-service teachers in introductory statistics. Journal of Statistics Education, 12(1).

[Online: http://www.amstat.org/publications/jse/v12n1/nasser.html]

Ramirez, C., Schau, C., \& Emmioğlu, E. (2012). The importance of attitudes in statistics education. Statistics Education Research Journal, 11(2).

[Online: http://www.stat.auckland.ac.nz/ iase/serj/SERJ11\%282\%29_Ramirez.pdf]

Rosenthal, R. (1995). Writing meta-analytic reviews. Psychological Bulletin, 118(2), 183-192.

Schau, C. (1992). Survey of Attitudes Toward Statistics (SATS-28).

[Online: http://evaluationandstatistics.com/]

Schau, C. (2003a). Survey of Attitudes Toward Statistics (SATS-36).

[Online: http://evaluationandstatistics.com/]

Schau, C. (2003b, August). Students' attitudes: The "other" important outcome in statistics education. Paper presented at the Joint Statistical Meetings, San Francisco, CA.

[Online: http://evaluationandstatistics.com/JSM2003.pdf]

Schau, C., Stevens, J., Dauphinee, T. L., \& Del Vecchio, A. (1995). The development and validation of the Survey of Attitudes Toward Statistics. Educational and Psychological Measurement, 55(5), 868-875.

Schutz, P. A., Drogosz, L. M., White, V. E., \& Distefano, C. (1998). Prior knowledge, attitude, and strategy use in an introduction to statistics course. Learning \& Individual Differences, 10(4), 291308.

[Online: http://dx.doi.org/10.1016/S1041-6080\%2899\%2980124-1]

Scott, J. S. (2001). Modeling aspects of students' attitudes and performance in an undergraduate introductory statistics course (Unpublished doctoral dissertation). University of Georgia, Athens, GA.

Sizemore, O. J., \& Lewandowski, G. (2009). Learning might not equal liking: Research methods course changes knowledge but not attitudes. Teaching of Psychology, 36(2), 90-95.

Sorge, C., \& Schau, C. (2002, April). Impact of engineering students' attitudes on achievement in statistics: A structural model. Paper presented at the annual meeting of the American Educational Research Association, New Orleans.

Stone, A., Allen, K., Rhoads, T. R., Murphy, T. J., Shehab, R. L., Saha, C. (2003, November). The statistics concept inventory: A pilot study. Paper presented at the $33^{\text {rd }}$ ASEE/IEEE Frontiers in Education Conference, Boulder, CO.

Tempelaar, D. T., Gijselaers, W. H., \& Schim van der Loeff, S. (2006). Puzzles in statistical reasoning. Journal of Statistics Education, 14(1). 
[Online: www.amstat.org/publications/jse/v14n1/tempelaar.html]

Tempelaar, D. T., Schim van der Loeff, S., \& Gijselaers, W. H. (2007). A structural equation model analyzing the relationship of students' attitudes toward statistics, prior reasoning abilities and course performance. Statistics Education Research Journal, 6(2), 78-102.

[Online: http://www.stat.auckland.ac.nz/ iase/serj/SERJ6\%282\%29_Tempelaar.pdf]

Verhoeven, P. S. (2009). Quality in statistics education: Determinants of course outcomes in methods \& statistics education at universities and colleges (Unpublished doctoral dissertation). Amsterdam: Boom Onderwijs.

Wigfield, A., \& Eccles, J. S. (2002). The development of competence beliefs, expectancies for success, and achievement values from childhood through adolescence. In A. W. J. S. Eccles (Ed.), Development of achievement motivation. San Diego, CA: Academic Press.

Zimprich, D. (2012). Attitudes toward statistics among Swiss psychology students. Swiss Journal of Psychology, 71(3), 149-155.

ESMA EMMIOĞLU

Gaziosmanpasa University

Department of Educational Sciences

Tokat, Turkey 